Nancy, his three sons and his four granddaughters.

BENAIM, S. (1983) The Italian Experiment. Psychiatric Bulletin, 7,7-10.
BENAIM, S., HORDER, J. \& ANDERSON, J. (1973) Hysterical epidemic in a classroom. Psychological Medicine, 3, 366-373.

PAGE, C., BENAIM, S. \& LAPPIN, F. (1987) A long-term retrospective follow-up study of patients treated with prophylactic lithium carbonate. British Journal of Psychiatry, 150, 175-179.

Gerald Russell

columns

\title{
obituary
}

\section{Brian Lake}

\section{Formerly Consultant Psychotherapist, Leeds}

Brian was born in 1922 into a religious family who lived near Liverpool where his father was a jobber at the Liverpool Stock Exchange. He was the youngest of three brothers of whom the eldest, Frank, like Brian, studied medicine with a view to becoming a missionary in India. Brian began his studies in Edinburgh in 1940 and qualified with the 'Scottish Triple' in 1945. After house jobs at the Edinburgh Royal Infirmary and a period as Senior R.M.O. at the Royal Liverpool Children's Hospital. He was rejected for military service on medical grounds, so he decided to go to sea; he served with the Cunard White Star Line for the greater part of the 1950s. However, it was his contact with the crew and his involvement in negotiations to settle conflicts between them which most interested him and led to him to develop an interest in psychiatry. In the late 1950s he joined the junior staff at Warlingham Park Hospital in Surrey where he found himself among a stimulating group of trainees, many of whom later became distinguished in the psychiatric world. He obtained the DPM in 1961.

After training in psychiatry, Brian joined his brother Frank, who had established the Clinical Theology Association, in Nottingham. This organisation was concerned in the training of ministers of religion in the management of the kind of emotional and psychiatric problems which they encountered in their pastoral work. At the same time, Brian worked as a psychotherapist in prisons as well as in private practice. However, Frank developed some extreme views in both the understanding of emotional problems and in their treatment which Brian felt unable

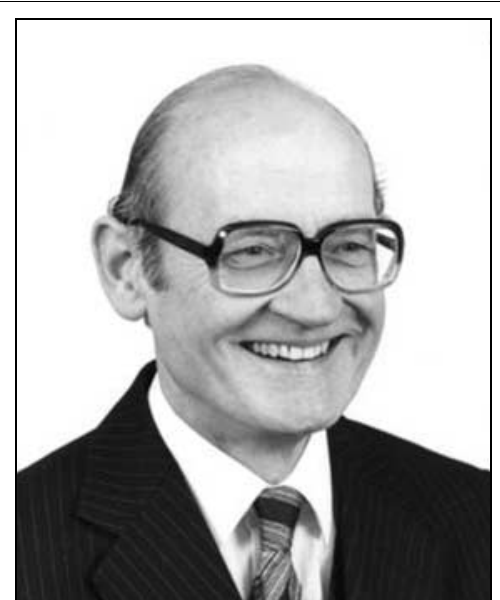

to share, which led to a professional rift between them and to Brian working independently. An important consequence of this rift led to Brian having a personal analysis by Dr Harry Guntrip, a psychologist and minister of religion himself. Brian found his analysis with Guntrip to be personally beneficial and helpful in his clinical work. He obtained the MRCPsych in 1971

The establishment of the new medical school in Nottingham with a department of psychiatry, led in 1974 to the appointment of Dr Mark Aveline as consultant psychotherapist and to the establishment of a department of psychotherapy with responsibility for the provision of a service and for teaching a range of disciplines. Brian participated in these developments and had experience of the tasks involved. He was himself later appointed Consultant Psychotherapist to the Leeds hospitals in 1980, based at St James's University Hospital, facing similar tasks to those he had encountered in Nottingham. At much the same time, Brian married (for the first time at the age of 58) Dr Dorothy Heard, herself a consultant child psychiatrist who had previously worked with the eminent Dr Bowlby at the Tavistock Clinic. This occasioned surprise and delight among Brian's family, friends and colleagues; overnight he became a step-father and step-grandfather, roles which he took to with alacrity.

In Leeds, Brian succeeded Dr Ronald Markillie, a psychoanalyst, who in a parttime capacity had been the main source of influence and teaching in psychotherapy in Yorkshire since the Second World War.

Brian's task was to establish a new department of psychotherapy, to provide a psychotherapy service - where there had previously been none - and to teach medical undergraduates and trainees from various disciplines. He succeeded and by his retirement in 1987 he had established a department which fulfilled these requirements.

Retirement led to a period of great creativity. Brian and Dorothy continued their extensive teaching activities in psychotherapy and to develop their theoretical approach to the subject according to attachment theory. Their work was published in a book The Challenge of Attachment Theory for Care Giving in 1997. (The development of their ideas is due to be published in 2008.) They made such an important contribution to teaching in the Department of Social Studies at the University of York that their work was recognised by the award of the degree of a doctorate to both of them in 2001, an almost unique eventuality. Brian died on 14 December 2007 after suffering from vascular disease for a number of years. He will be much missed but well remembered.

\section{R. H. S. Mindham} A. C. P. Sims

doi: 10.1192/pb.bp.108.021618 